\title{
Thirty-day readmission rates in spine surgery: systematic review and meta-analysis
}

\author{
James T. Bernatz, BS, and Paul A. Anderson, MD \\ Department of Orthopedics and Rehabilitative Medicine, University of Wisconsin School of Medicine and Public Health, \\ Madison, Wisconsin
}

\begin{abstract}
OBJECT The rate of 30-day readmissions is rapidly gaining significance as a quality metric and is increasingly used to evaluate performance. An analysis of the present 30-day readmission rate in the spine literature is needed to aid the development of policies to decrease the frequency of readmissions. The authors examine 2 questions: 1) What is the 30 day readmission rate as reported in the spine literature? 2) What study factors impact the rate of 30-day readmissions?

METHODS This study was registered with Prospero (CRD42014015319), and 4 electronic databases (PubMed, Cochrane Library, Web of Science, and Google Scholar) were searched for articles. A systematic review and meta-analysis was performed to assess the current 30-day readmission rate in spine surgery. Thirteen studies met inclusion criteria. The readmission rate as well as data source, time from enrollment, sample size, demographics, procedure type and spine level, risk factors for readmission, and causes of readmission were extrapolated from each study.
\end{abstract}

RESULTS The pooled 30-day readmission rate was 5.5\% (95\% Cl 4.2\%-7.4\%). Studies from single institutions reported the highest 30 -day readmission rate at $6.6 \%(95 \% \mathrm{Cl} 3.8 \%-11.1 \%)$, while multicenter studies reported the lowest at $4.7 \%$ $(95 \% \mathrm{Cl} 2.3 \%-9.7 \%)$. Time from enrollment had no statistically significant effect on the 30 -day readmission rate. Studies including all spinal levels had a higher 30 -day readmission rate $(6.1 \%, 95 \% \mathrm{Cl} 4.1 \%-8.9 \%)$ than exclusively lumbar studies (4.6\%, 95\% Cl 2.5\%-8.2\%); however, the difference between the 2 rates was not statistically significant $(p=$ $0.43)$. The most frequently reported risk factors associated with an increased odds of 30-day readmission on multivariate analysis were an American Society of Anesthesiology score of 4+, operative duration, and Medicare/Medicaid insurance. The most common cause of readmission was wound complication (39.3\%).

CONCLUSIONS The 30 -day readmission rate following spinal surgery is between $4.2 \%$ and $7.4 \%$. The range, rather than the exact result, should be considered given the significant heterogeneity among studies, which indicates that there are factors such as demographics, procedure types, and individual institutional factors that are important and affect this outcome variable. The pooled analysis of risk factors and causes of readmission is limited by the lack of reporting in most of the spine literature.

http://thejns.org/doi/abs/10.3171/2015.7.FOCUS1534

KEY WORDS spine; neurosurgery; orthopedics; thirty-day readmission

$\mathrm{T}$ HE Centers for Medicare \& Medicaid Services (CMS) has targeted 30-day readmissions as a source of unnecessary costs. ${ }^{1}$ According to the Medicare Payment Advisory Committee, nearly 20\% of all Medicare patients hospitalized in 2008 were readmitted within 30 days of discharge, costing $\$ 17.4$ billion. ${ }^{20}$ Recent pilot programs such as the Hospital Readmissions Reduction Program (HRRP; https://www.cms.gov/Medicare/ medicare-fee-for-service-payment/acuteinpatientPPS/ readmissions-reduction-program.html) and the Bundled
Payments for Care Improvement Initiative (http://innova tion.cms.gov/initiatives/bundled-payments/) have altered the Medicare reimbursement model to decrease payments to hospitals with excessive 30-day readmissions. ${ }^{10,13}$ The HRRP initially included admissions for myocardial infarction, heart failure, and pneumonia, but will expand as of fiscal year 2015 to include chronic obstructive pulmonary disease and total hip and knee replacement. ${ }^{1}$ Spine surgery as a high-cost procedure is likely to be targeted similarly in the future. With health care reform now reaching mul-

ABBREVIATIONS ASA = American Society of Anesthesiologists; CMS = Centers for Medicare \& Medicaid Services; HRRP = Hospital Readmissions Reduction Program; $\mathrm{MeSH}=$ Medical Subject Headings; NSQIP = National Surgical Quality Improvement Program; SSI = surgical site infection.

SUBMITTED January 28, 2015. ACCEPTED July 23, 2015.

INCLUDE WHEN CITING DOI: 10.3171/2015.7.FOCUS1534. 
tiple specialties, many quality improvement efforts have been aimed at reducing 30-day readmissions.

The orthopedic and neurosurgical spine literature has mainly reported 30-day readmission rates based on procedure, with rates ranging from $2.5 \%$ for anterior cervical discectomy and fusion ${ }^{12}$ to $14.2 \%$ for primary and metastatic spine tumors. ${ }^{26}$ With such a broad range of procedure-based readmission rates, it is difficult to determine the overall incidence of 30-day readmissions in spinal surgery and thus difficult to develop quality improvement initiatives to reduce the 30-day readmission rate. Further determination of the causes and risk factors is essential for improvement processes to occur.

Our overall goal is to reduce 30-day readmissions. The aim of this study was to understand the rate of 30-day readmissions in spine surgery and examine risk factors and causes of 30-day readmission. We proposed 2 questions: 1) What is the 30-day readmission rate as reported in the spine literature? 2) What study factors impact the rate of 30-day readmissions?

\section{Methods}

\section{Electronic Literature Search}

This study was registered with Prospero, an international database of prospectively registered systematic reviews (CRD42014015319, 12/2/2014). Four electronic databases (PubMed, Cochrane Library, Web of Science, and Google Scholar) were searched for published English-language articles using the Medical Subject Headings (MeSH) used by the National Library of Medicine (Fig. 1). The same MeSH terms were used in all 4 databases: "(patient readmission OR readmission*) AND (30 day* OR thirty day* OR 30-day* OR thirty-day*) AND (spine OR lumbar OR cervical OR thoracic OR sacral)." This search yielded 120 results. The Web of Science produced 2 additional nonduplicate studies, while the Cochrane Library and Google Scholar did not produce any nonduplicate studies. The combined 122 studies were subject to title and/or abstract review. Seventy-six articles were eliminated because the abstract did not mention readmissions or did not report on spine procedures. The remaining 46 articles underwent full-text evaluation by a single author. Thirty-three studies were eliminated based on exclusion criteria outlined below; therefore, 13 publications were included in this analysis.

The inclusion criteria were quantitative reporting of 30day readmissions following any spinal procedure (orthopedic or neurological) and the inclusion of inpatient-only procedures or both inpatient and outpatient procedures. There were no restrictions on the study design; however, all studies were found to be retrospective.

The exclusion criteria were publication outside of the United States, data collection before the year 2000, and inclusion of fewer than 100 study patients. Exclusively cervical spine studies were not included. Studies were also excluded if the patient population had already been subgrouped (for example, diabetic patients undergoing laminectomy) or if the article was reporting on a specific medical device or surgical technique. Deformity studies were not excluded because they report on multiple surgical techniques.

\section{Data Extraction}

The following data were extracted: data source, time from enrollment, sample size, demographics (age and sex), 30-day readmissions, procedure type and spine level, risk factors for readmission, and causes of readmission. The data source was categorized as a single hospital's database, a multicenter registry database (collecting data on 2-100 hospitals), or a large national database (CMS, Veterans Affairs, and National Surgical Quality Improvement Program [NSQIP]). The time of data collection, which we refer to as the "time from enrollment," was grouped into 3 categories of 4-year increments: after 2009, between 2006 and 2009, and before 2006. Because some studies reported readmissions within 30 days of the procedure and others reported those within 30 days of discharge, readmissions data were extracted according to either definition, and the definition used by each study was recorded. Procedure type and spine level were determined by reviewing the methods of each study. Risk factors based on multivariate analysis were collected when available. Correlation of risk factors with 30-day readmission was examined; correlations reported in 2 or more studies were statistically analyzed. Causes of readmission were pooled from studies that reported these data, and only causes identified in 2 or more studies were analyzed. The causes were grouped into 3 categories: wound related, surgical, and medical system. Because some of the causes had overlap, the total percentage of readmissions does not sum to $100 \%$. All quantitative values were recorded as the mean and the $95 \%$ confidence interval.

\section{Data Analysis}

Comprehensive Meta-Analysis, version 2.2050 (Biostat) was used for data pooling. Sensitivity analysis was performed by the sequential removal of all studies from the analysis. An a priori threshold of $0.5 \%$ was chosen; thus, if removing a study changed the 30-day readmission rate by $0.5 \%$ or more, this was considered clinically significant. Inverse funnel plots were used to visually assess publication bias. Duval and Tweedie's trim and fill method was used to impute studies potentially missing from the analysis and to recompute the combined random effect. Further quantitative measurement of publication bias was accomplished with the file-drawer analysis of the classic fail safe as well as Orwin's fail safe. To assess historical changes and determine a correlation between the date of patient enrollment and the 30-day readmission rate, a method of moments meta-regression was used.

All confidence intervals were reported at $95 \%$. Statistical significance was measured at a $p$ value of 0.05 . Heterogeneity was assessed by calculating the Cochrane Q value and the I-squared statistic. I-squared values of $25 \%$, $50 \%$, and $75 \%$ were considered indicative of low, moderate, and high heterogeneity, respectively. The studies were assumed to be heterogeneous; therefore, a random effects model was chosen a priori.

\section{Results}

\section{Systematic Review}

We identified 13 studies reporting 30-day readmissions following spine surgery (Fig. 1). The total number of in- 


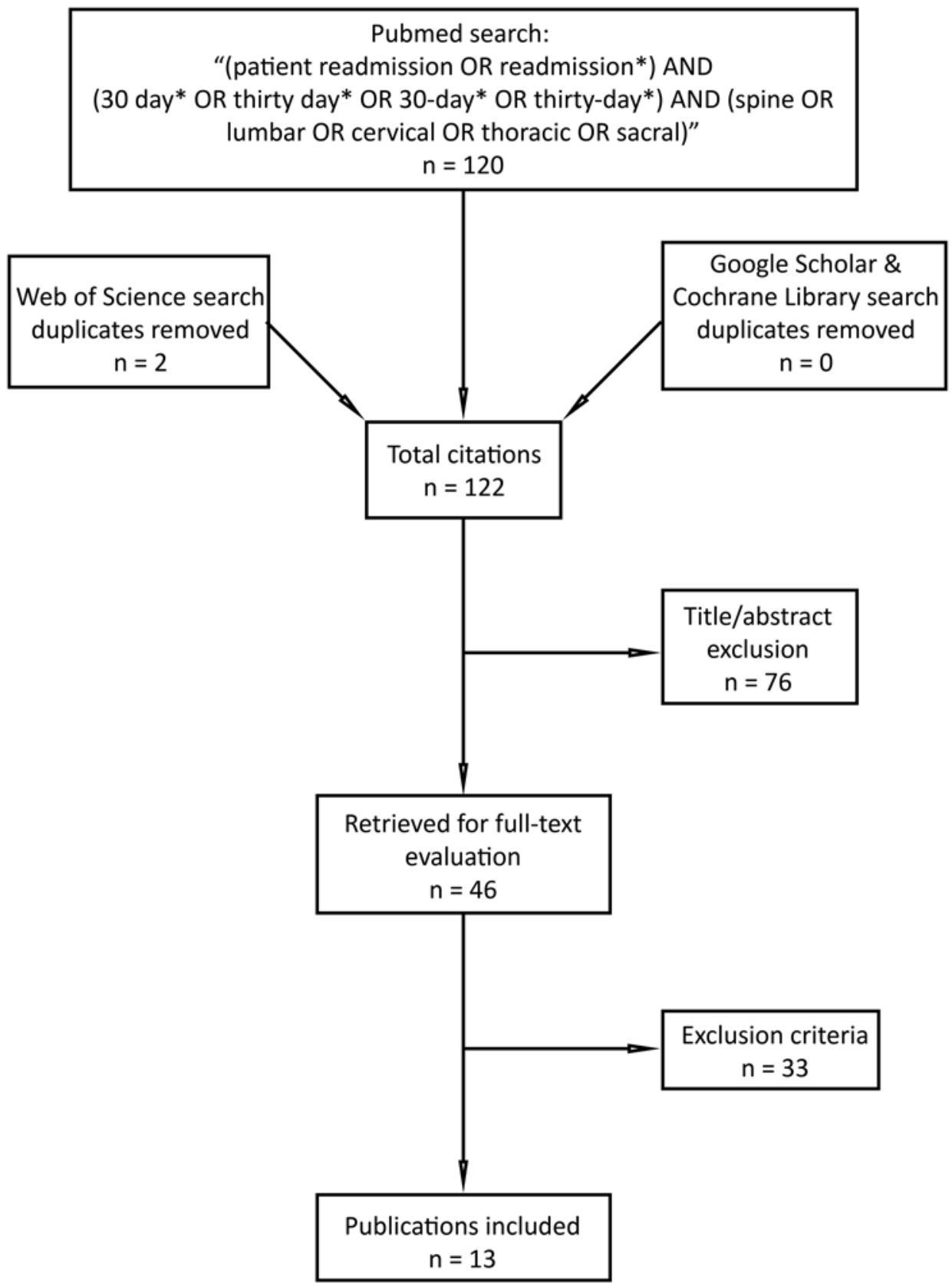

FIG. 1. Flowchart of systematic review methodology.

cluded patients was 488,049 , with studies ranging from 197 to 343,068 patients (Table 1). Five studies used data from a single institution, 3 used data from a multicenter registry, and the remaining 5 used data from a large national database. The majority (9) of the studies reported surgeries on all spine levels, while the remaining 4 exclusively reported on the lumbar spine. Two studies included only deformity patients.

\section{Thirty-Day Readmissions}

The pooled 30-day readmission rate for the 13 studies was $5.5 \%$ (95\% CI $4.2 \%-7.4 \%$ ) and varied from $2.6 \%$ to 14.2\% (Fig. 2 and Table 2). Heterogeneity was high, with an I-squared value of $99.6 \%$. The pooled mean patient age was 57.9 years (standard error of the mean 9.4 years). There was high heterogeneity among the studies based on patient age, with an I-squared value of $99.9 \%$. Eliminating the exclusively pediatric study did not change the heterogeneity. The mean percent of males was $44.7 \%$ (95\% CI $40.7 \%-48.7 \%$ ) with a range from $29.2 \%$ to $60.0 \%$. There was high heterogeneity based on patient sex, with an Isquared value of $99.6 \%$.

\section{Publication Bias}

The inverse funnel plot for publication bias shows that there are studies missing to the right of average, meaning 
TABLE 1. Evidentiary table*

\begin{tabular}{|c|c|c|c|c|c|c|}
\hline Authors \& Year & Level & Procedure & Data Source & $\begin{array}{l}\text { Data Collection } \\
\text { Period }\end{array}$ & $\begin{array}{c}\text { No. of } \\
\text { Patients }\end{array}$ & $\begin{array}{c}\text { No. of } \\
\text { Readmissions } \\
(\%)\end{array}$ \\
\hline Amin et al., 2013 & All & All & Single institution & Oct 2007-Jun 2011 & 5780 & $281(4.9)$ \\
\hline Basques et al., 2014 & Lumbar & Laminectomy & National database & Jan 2011-Dec 2012 & 2339 & $87(3.7)$ \\
\hline Bekelis et al., 2014 & Lumbar & Discectomy & Multicenter registry & Jan 2007-Dec 2008 & 27,174 & $1588(5.8)$ \\
\hline Kim et al., 2014 & Lumbar & Decompression & National database & Jan 2011-Dec 2011 & 7016 & $314(4.5)$ \\
\hline $\begin{array}{l}\text { McCormack et al., } \\
2012\end{array}$ & All & All & Single institution & Jan 2007-Dec 2009 & 3673 & $156(4.2)$ \\
\hline Pugely et al., $2014^{21}$ & All & Deformity & Multicenter registry & Jan 2012-Dec 2012 & 2005 & $79(3.9)$ \\
\hline Pugely et al., $2014^{22}$ & Lumbar & All & Multicenter registry & Jan 2012-Dec 2012 & 15,668 & $695(4.4)$ \\
\hline Schairer et al., 2013 & All & Deformity & Single institution & Jan 2006-Dec 2011 & 836 & $116(13.9)$ \\
\hline Schairer et al., 2014 & All & Tumor & Single institution & Jan 2005-Dec 2011 & 197 & $28(14.2)$ \\
\hline Seicean et al., 2014 & All & $\begin{array}{l}\text { Fusion, laminectomy, or } \\
\text { both }\end{array}$ & National database & Jan 2006-Dec 2012 & 49,314 & $1283(2.6)$ \\
\hline Toy et al., 2014 & All & Vertebroplasty & National database & Jan 2011-Dec 2012 & 850 & $92(10.8)$ \\
\hline Voskuijl et al., 2014 & All & All & Single institution & Jan 2008-Dec 2011 & 30,129 & $913(3.0)$ \\
\hline Wang et al., 2012 & All & All & National database & Jan 2003-Dec 2007 & 343,068 & $27,102(7.9)$ \\
\hline Total & & & & & 488,049 & 32,734 \\
\hline
\end{tabular}

* All studies were retrospective observational studies.

that there is a lack of studies with higher readmission rates (Fig. 3). Using trim and fill for the random effects model, there is 1 study missing to the right of average and the imputed point estimate readmission rate is $5.1 \%$, which by the a priori definition is not a significant change from $5.5 \%$. Orwin's fail safe indicates that 6 studies with a 30 - day readmission rate of $2.0 \%$ would be needed to lower the fixed model readmission rate of $7.1 \%$ below $5.0 \%$.

\section{Data Source}

The studies were grouped into 3 categories based on data source: single center, multicenter registry, and large

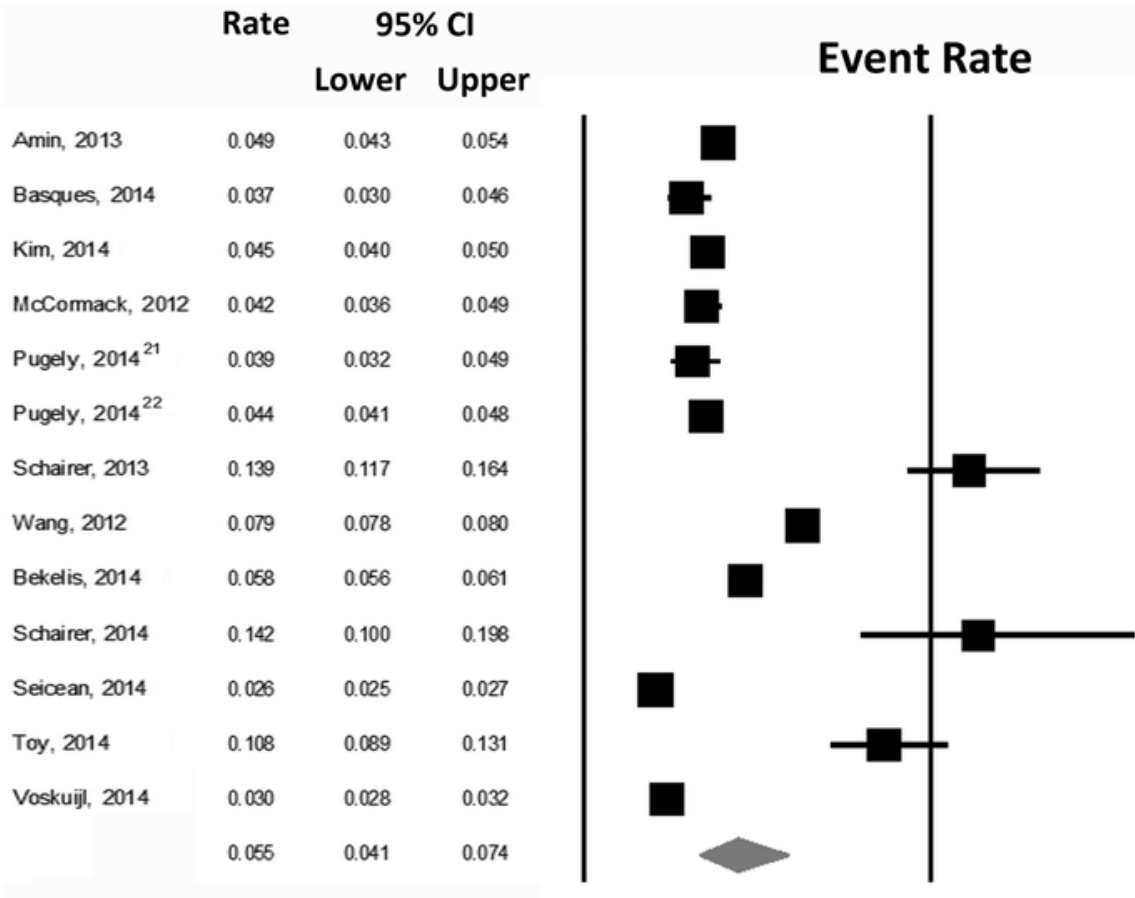

$0.0 \quad 0.125$

0.25

FIG. 2. Forest plot of the event (30-day readmission) rate with the $95 \%$ confidence interval. 
TABLE 2. Thirty-day readmission rates stratified by data source, time from enrollment, and spinal level

\begin{tabular}{|c|c|c|c|c|c|c|c|}
\hline Parameter & $\begin{array}{l}\text { No. of } \\
\text { Studies }\end{array}$ & $\begin{array}{c}\text { No. of } \\
\text { Patients }\end{array}$ & $\begin{array}{c}\text { Readmission } \\
\%\end{array}$ & 95\% CI Lower & 95\% Cl Upper & Cochran's $Q$ & I-squared (\%) \\
\hline Pooled results & 13 & 488,049 & 5.5 & 4.2 & 7.4 & 2965.5 & 99.6 \\
\hline \multicolumn{8}{|l|}{ Data source } \\
\hline Single hospital & 5 & 40,615 & 6.6 & 3.8 & 11.1 & 313.1 & 98.7 \\
\hline Multicenter & 3 & 44,847 & 4.7 & 2.3 & 9.3 & 46.6 & 95.7 \\
\hline National & 5 & 402,587 & 5.2 & 3.0 & 8.8 & 1768.1 & 99.8 \\
\hline \multicolumn{8}{|l|}{ Enrollment date } \\
\hline After Dec 31, 2009 & 5 & 27,878 & 5.0 & 3.4 & 7.4 & 77.1 & 94.8 \\
\hline Jan 1, 2006 to Dec 31, 2009 & 6 & 116,906 & 4.9 & 3.4 & 7.0 & 752.1 & 99.3 \\
\hline Before Jan 1, 2006 & 2 & 343,265 & 10.4 & 5.6 & 18.5 & 10.4 & 90.4 \\
\hline \multicolumn{8}{|l|}{ Level } \\
\hline All & 9 & 435,852 & 6.1 & 4.1 & 8.9 & 2609.7 & 99.6 \\
\hline Lumbar & 4 & 52,197 & 4.6 & 2.5 & 8.2 & 59.1 & 94.9 \\
\hline
\end{tabular}

national database. The single-institution studies reported the highest 30-day readmission rate at $6.6 \%(95 \% \mathrm{CI}$ $3.8 \%-11.1 \%$ ), while the multicenter studies reported the lowest at $4.7 \%$ (95\% CI 2.3\%-9.3\%; Table 2). The large national databases had the largest number of patients $(402,587)$ and a 30 -day readmission rate of $5.2 \%(95 \% \mathrm{CI}$ $3.0 \%-8.8 \%)$. There was no significant difference in readmission rates based on data source $(p=0.72)$. Heterogeneity was high with an I-squared value of $99.6 \%$.

\section{Time From Enrollment}

The 30-day readmission rates were compared based on the time that the studies started collecting data. The most recent studies, which began collecting data after 2009, had a 30-day readmission rate of $5.0 \%$ (95\% CI 3.4\%-7.4\%; Table 2). Studies that began collecting data between 2006 and 2009 had a readmission rate of $4.9 \%$ (95\% CI 3.4\%$7.0 \%$ ), while the oldest studies, which began collecting data before 2006, had a readmission rate of $10.4 \%(95 \%$ CI 5.6\%-18.5\%). Although the oldest studies had a higher 30-day readmission rate, this was not statistically significant $(\mathrm{p}=0.098)$.

\section{Spine Level}

Studies were categorized as exclusively lumbar or studies that included all spinal levels. Studies including all spinal levels had a higher 30-day readmission rate at $6.1 \%$ (95\% CI 4.1\%-8.9\%; Table 2) than exclusively lumbar studies at $4.6 \%$ (95\% CI 2.5\%-8.2\%); however, the difference between the 2 rates was not statistically significant $(\mathrm{p}=0.43)$.

\section{Procedure}

No analysis could be performed based on procedure because no single procedure type was represented by a sufficient number of studies for meaningful analysis. The most frequent procedure types were deformity ( 2 studies) and laminectomy (2 studies).

\section{Risk Factors}

Sixteen risk factors were identified on multivariate analysis in at least 2 studies (Table 3). The risk factors positively associated with increased 30-day readmissions were an American Society of Anesthesiologists (ASA) physical status of 4 or greater (4 studies), operative duration (4), and Medicare/Medicaid insurance (3). Age was found to have a statistically positive correlation with increased readmission in 3 studies; however, no correlation was found in 2 other studies. Similarly, history of pulmonary disease was found to have a positive correlation with readmission in 3 studies but no correlation in 3 other studies. We had intended to perform multivariable meta-regression on these

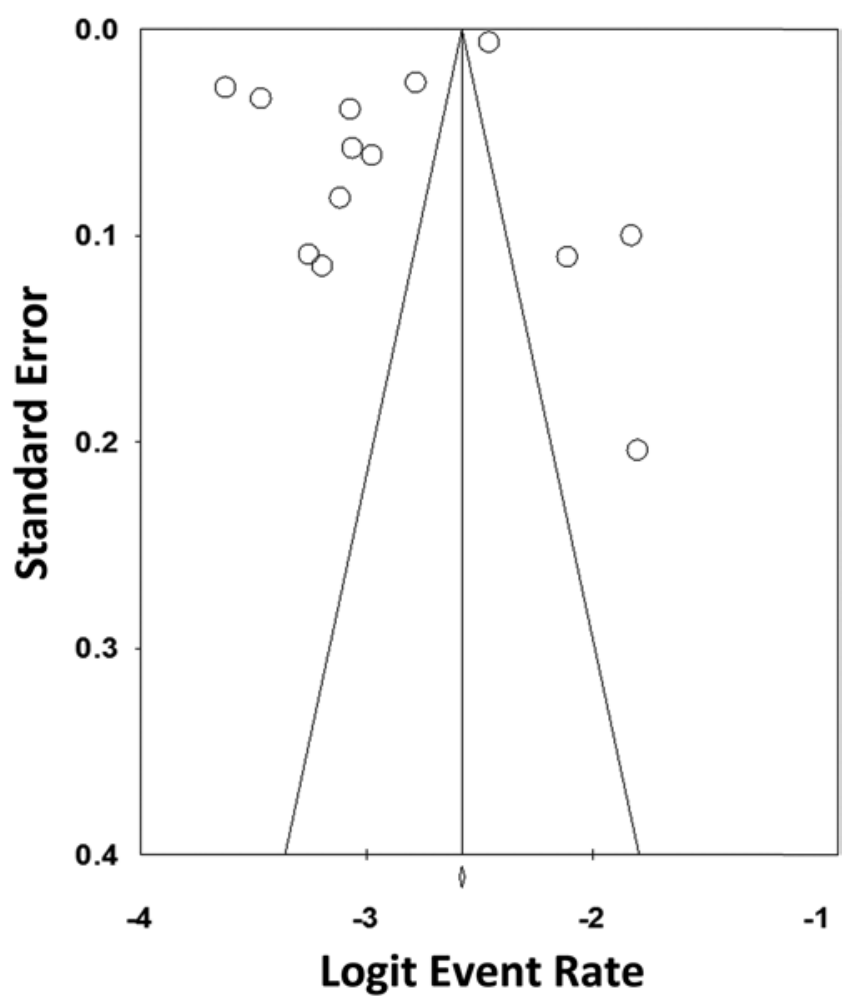

FIG. 3. Funnel plot assessing publication bias. Missing studies to the right of average demonstrate a lack of studies with higher readmission rates reported in the literature. 
factors, but we believed that there were too few studies with consistent reporting of the various factors to statistically justify this approach.

\section{Causes of Readmission}

Of the 13 causes of readmission identified in 2 or more studies, infection was the most common, accounting for $28.2 \%$ of the 30 -day readmissions (Table 4 ). This category included both surgical site infections (SSIs) as defined by the Centers for Disease Control and Prevention, and other infections (for example, deep space infections, bacteremia). Wound complications including SSIs, noninfectious wound problems, dehiscence, hematoma, and seroma accounted for $39.3 \%$ of 30 -day readmissions. The next most common cause of readmission was medical system complications at $26.6 \%$, which included adverse events such as deep venous thrombosis, pulmonary embolism, pneumonia, or urinary tract infection.

\section{Sensitivity Analysis}

We examined the effect of the meta-analysis model on the 30-day readmission rate. The fixed model readmission rate was $7.1 \%$, which was much greater than the random effects rate of $4.4 \%$. This was caused by the larger studies having greater weight in the fixed model. The Wang et al. study, which had a high 30-day readmission rate, accounted for $82 \%$ of the fixed model 30-day readmission rate and greatly increased the fixed model readmission rate. ${ }^{33}$ This justified the use of the random effects model.

Individual studies were removed from the analysis to assess for a significant change in the 30-day readmission rate based on the a priori definition; no individual study made a $0.5 \%$ difference. Removing the 5 studies from single institutions decreased the 30-day readmission rate to $4.9 \%$. Eliminating the 5 multicenter registry studies in- creased the rate to $6.1 \%$. Elimination of any other groups based on data source, time of enrollment, procedure type, or spine level did not significantly change the results.

\section{Discussion}

The principle aim of this study was to determine the 30 -day readmission rate in spine surgery, which we found to be $5.5 \%$ with a $95 \%$ CI between $4.2 \%$ and $7.4 \%$. There is significant heterogeneity and therefore it is best to consider the confidence interval rather than a single pooled result. Comparing other medical specialties, we found that this rate in absolute terms is 7\%-19\% lower than the rates reported in meta-analyses of general internal medicine and 5\% lower than rates for general surgery. ${ }^{4,14}$ This spine surgery 30-day readmission rate appears to be lower than the 30-day readmission rate for neurosurgery as a whole, which has been reported between $6.9 \%^{8}$ and $14 \%{ }^{31}$ for a single institution and $10.5 \%$ for the Veterans Affairs Surgical Quality Improvement Program. ${ }^{12}$ Our 5.5\% 30-day readmission rate is similar to the pooled readmission rate of $5.4 \%$ reported in a large meta-analysis of all orthopedic specialties.

We report on 30-day readmission rates after procedures by both neurosurgeons and orthopedic surgeons. Given the lack of studies reporting on spine surgeries performed only by neurosurgeons, we were unable to statistically examine the readmission rates of neurosurgeons as opposed to orthopedic surgeons. However, Seicean et al. found that in over 34,000 patients undergoing spine surgery in the NSQIP database, there was no difference in 30-day readmission rates between neurosurgeons and orthopedic surgeons (4.5\% vs 4.4\%, respectively). ${ }^{27}$ Similarly, McCutcheon et al. reported no difference in rates for 30-day returns to the operating room between the 2 specialties ( $4.0 \%$ neurosurgery vs $3.9 \%$ orthopedic surgery). ${ }^{19}$

TABLE 3. Risk factors for readmission

\begin{tabular}{|c|c|c|c|}
\hline Risk Factor & $\begin{array}{l}\text { No. of Studies w/ Statistically } \\
\text { Positive* Correlation }^{*}\end{array}$ & No. of Studies w/ No Correlation & No. of Studies Not Reporting \\
\hline ASA Status 4+ & 4 & 0 & 9 \\
\hline Op duration & 4 & 1 & 8 \\
\hline Medicare/Medicaid & 3 & 0 & 10 \\
\hline Age & 3 & 2 & 8 \\
\hline History of pulmonary disease & 3 & 3 & 7 \\
\hline $\mathrm{CCl}$ & 2 & 0 & 11 \\
\hline Depression & 2 & 0 & 11 \\
\hline Increased BMI & 2 & 0 & 11 \\
\hline Serum creatinine $>1.2 \mathrm{mg} / \mathrm{dl}$ & 2 & 0 & 11 \\
\hline Diabetes & 2 & 2 & 9 \\
\hline History of heart disease & 1 & 1 & 11 \\
\hline ASA Status 3-4 & 1 & 1 & 11 \\
\hline Length of stay in ICU & 1 & 1 & 11 \\
\hline Recent weight loss & 1 & 1 & 11 \\
\hline Steroid use & 1 & 1 & 11 \\
\hline Anemia & 1 & 2 & 10 \\
\hline
\end{tabular}


TABLE 4. Pooled causes of readmission

\begin{tabular}{|c|c|c|c|c|c|c|}
\hline Cause & $\begin{array}{l}\text { No. of Studies } \\
\text { Reporting }\end{array}$ & $\begin{array}{c}\text { No. of Readmissions } \\
\text { w/ Diagnosis* }\end{array}$ & $\begin{array}{c}\text { Total No. of } \\
\text { Readmissions } †\end{array}$ & Readmissions \% & $\begin{array}{c}95 \% \mathrm{Cl} \\
\text { Lower }\end{array}$ & $\begin{array}{l}95 \% \mathrm{Cl} \\
\text { Upper }\end{array}$ \\
\hline \multicolumn{7}{|l|}{ Wound-related } \\
\hline Infection & 7 & 4783 & 30,025 & 28.2 & 19.4 & 39.1 \\
\hline SSI & 2 & 67 & 144 & 20.3 & 0.7 & 89.3 \\
\hline Noninfectious wound problem & 6 & 176 & 2923 & 8.1 & 4.7 & 13.6 \\
\hline Dehiscence & 4 & 27 & 1888 & 2.7 & 1.1 & 6.4 \\
\hline Hematoma & 4 & 1013 & 28,069 & 3.6 & 3.4 & 3.8 \\
\hline Seroma & 4 & 37 & 811 & 4.6 & 3.3 & 6.2 \\
\hline \multicolumn{7}{|l|}{ Surgical } \\
\hline Dural tear & 5 & 46 & 1276 & 4.9 & 2.4 & 6.9 \\
\hline Fixation failure & 4 & 56 & 995 & 7.1 & 2.4 & 18.8 \\
\hline Pain & 5 & 209 & 2554 & 6.9 & 1.8 & 22.7 \\
\hline \multicolumn{7}{|l|}{ Medical } \\
\hline Medical complication & 4 & 11,105 & 28,069 & 26.6 & 17.7 & 37.8 \\
\hline DVT & 2 & 27 & 851 & 2.7 & 1.1 & 6.6 \\
\hline Coagulopathy & 1 & 65 & 695 & 9.4 & 7.4 & 11.8 \\
\hline UTI & 2 & 24 & 2283 & 1.1 & 0.6 & 2.1 \\
\hline
\end{tabular}

Heterogeneity in meta-analyses affords the opportunity to examine factors that may cause effect size variability. In the current study, patient age, sex, procedure type, level of surgery, data source, surgeon training, and time from enrollment were all different in the included studies and thus probably the causes of the heterogeneity. These factors probably contribute to the I-squared value consistently greater than $90 \%$. Because of inconsistent reporting, we were unable to perform subgroup analysis on the above variables except for data source, time from enrollment, and level of surgery. Removing studies reporting on data from single institutions decreases the pooled readmission rate by $0.6 \%$, thereby demonstrating that single-institution studies generally have a higher 30 -day readmission rate. This could be attributable to the fact that single-institution studies are more likely to report readmissions based on chart review and not on ICD-9 or current procedural terminology (CPT) coding, which have both been shown to have inaccuracies. ${ }^{18,24}$ The earlier studies (starting enrollment before 2006) do not have statistically significant higher effect sizes than later studies, which is surprising considering that increasingly more attention is devoted to reducing readmissions in both recent policy and the literature. The lack of statistical significance could be attributed to the small number of studies (only 2) from this time period, but the absence of studies older than 10 years is expected since the 30-day readmission rate was not a commonly reported quality metric at that time. More recent data may include lower readmission rates given that minimally invasive microsurgical techniques have become more popular. Future studies examining 30-day readmission rates following minimally invasive spine surgery, as well as risk factors and causes of readmission, are warranted.

Based on the data made available by the 13 studies included in our analysis, ASA score, operative duration, and Medicare/Medicaid insurance are the risk factors most often statistically correlated with increased odds of 30-day readmission. In patients with a high ASA score, comprehensive optimization programs of medical comorbidities have been shown to reduce complications, including readmissions. ${ }^{11,28}$ Moreover, our results suggest that an increased ASA score with its attendant risk should be considered at the time of surgical decision making. Conversely, operative duration is a surgical variable that should be limited when possible. Having 2 experienced spine surgeons for complex surgery such as deformity has been shown to reduce operative time and the risk of complications and therefore represents a potential method of limiting operative duration in high-risk spine procedures. ${ }^{2}$ We had aimed to perform multivariable meta-regression on these factors, but the scarcity of studies with consistent reporting of the various factors prevented this analysis. The reporting of readmission risk factors in future studies would be beneficial.

The pooled causes of readmission elucidate potential targets for 30-day readmission reduction. Forty percent of readmissions are for wound problems, the majority of which are surgical site infections. Recent literature has highlighted many strategies to reduce infectious complications including screening programs for methicillinresistant Staphylococcus aureus, ${ }^{23}$ decolonization, ${ }^{9}$ operating room air quality optimization, ${ }^{29}$ and compliance with antibiotics. ${ }^{16}$ To our knowledge, these strategies have not been trialed in spine surgery and thus warrant further study. Although dural tear is the cause of only $4.9 \%$ of readmissions in studies reporting these data, it represents a surgical complication unique to spinal surgery that is theoretically preventable. Yoshihara et al. report that in spinal 
surgery, those with a dural tear had higher in-hospital mortality and care costing $\$ 13,330$ more than those without a dural tear. ${ }^{34}$ It should be noted that risk factors and causes of readmission are not reported in the majority of studies; the conclusions drawn represent only what can be determined from the available data.

Our study has several limitations. First, because of the different coding used by the various databases, there are inconsistent definitions for the studied variables, which makes combining them for meta-analysis difficult. For example, some studies were able to report on readmissions to outside hospitals whereas others were not. Further, while the majority of studies reported readmissions 30 days from discharge, some reported readmissions 30 days from the procedure. This may have affected the pooled 30-day readmission rate. Similarly, many risk factors and causes of readmission have unclear definitions that potentially allow some groups to have overlap while others are excluded. Standard definitions would be useful for future studies. As stated above, the majority of studies only report readmission rates and do not include analyses of risk factors and causes. Therefore, the present study represents what is available in the literature but not necessarily in all of spine surgery. A single author extrapolated the data used for this analysis. Although the data were generally taken directly from figures and tables, a second reviewer might have optimized accuracy and the completeness of data extraction. Another limitation is the design of all included studies. The publications are retrospective observational studies, which are generally prognostic level II and represent moderate evidence.

\section{Conclusions}

This study reports the 30-day readmission rate following spinal surgery to be between $4.2 \%$ and $7.4 \%$. We recommend consideration of the confidence interval given the significant heterogeneity between studies. The heterogeneity indicates that there are factors such as demographics, procedure types, and individual institutional factors that are important and that affect this outcome variable. In the future, quantifying these factors and the effects of best practices may aid the development of quality improvement programs. The pooled analysis of risk factors and causes of readmission is limited by the lack of reporting in most spine literature.

\section{References}

1. American Hospital Association: Hospital Readmissions Reduction Program Fact Sheet, 4/14/14. (http://www.aha.org/ content/13/fs-readmissions.pdf) [Accessed August 4, 2015]

2. Ames CP, Barry JJ, Keshavarzi S, Dede O, Weber MH, Deviren V: Perioperative outcomes and complications of pedicle subtraction osteotomy in cases with single versus two attending surgeons. Spine Deform 1:51-58, 2014

3. Amin BY, Tu TH, Schairer WW, Na L, Takemoto S, Berven S, et al: Pitfalls of calculating hospital readmission rates based on nonvalidated administrative data sets: presented at the 2012 Joint Spine Section Meeting: clinical article. J Neurosurg Spine 18:134-138, 2013

4. Au AG, Padwal RS, Majumdar SR, McAlister FA: Patient outcomes in teaching versus nonteaching general internal medicine services: a systematic review and meta-analysis. Acad Med 89:517-523, 2014

5. Basques BA, Varthi AG, Golinvaux NS, Bohl DD, Grauer JN: Patient characteristics associated with increased postoperative length of stay and readmission after elective laminectomy for lumbar spinal stenosis. Spine (Phila Pa 1976) 39:833-840, 2014

6. Bekelis K, Missios S, Kakoulides G, Rahmani R, Simmons $\mathrm{N}$ : Selection of patients for ambulatory lumbar discectomy: results from four US states. Spine J 14:1944-1950, 2014

7. Bernatz JT, Tueting JL, Anderson PA: Thirty-day readmission rates in orthopedics: a systematic review and meta-analysis. PLoS One 10:e0123593, 2015

8. Buchanan CC, Hernandez EA, Anderson JM, Dye JA, Leung M, Buxey F, et al: Analysis of 30-day readmissions among neurosurgical patients: surgical complication avoidance as key to quality improvement. J Neurosurg 121:170-175, 2014

9. Chen AF, Heyl AE, Xu PZ, Rao N, Klatt BA: Preoperative decolonization effective at reducing staphylococcal colonization in total joint arthroplasty patients. J Arthroplasty 28 (8 Suppl):18-20, 2013

10. Delisle DR: Big things come in bundled packages: implications of bundled payment systems in health care reimbursement reform. Am J Med Qual 28:339-344, 2013

11. Halpin RJ, Sugrue PA, Gould RW, Kallas PG, Schafer MF, Ondra SL, et al: Standardizing care for high-risk patients in spine surgery: the Northwestern high-risk spine protocol. Spine (Phila Pa 1976) 35:2232-2238, 2010

12. Han S, Smith TS, Gunnar W: Descriptive analysis of 30-day readmission after inpatient surgery discharge in the Veterans Health Administration. JAMA Surg 149:1162-1168, 2014

13. Joynt KE, Orav EJ, Jha AK: Thirty-day readmission rates for Medicare beneficiaries by race and site of care. JAMA 305:675-681, 2011

14. Kassin MT, Owen RM, Perez SD, Leeds I, Cox JC, Schnier $\mathrm{K}$, et al: Risk factors for 30-day hospital readmission among general surgery patients. J Am Coll Surg 215:322-330, 2012

15. Kim BD, Smith TR, Lim S, Cybulski GR, Kim JY: Predictors of unplanned readmission in patients undergoing lumbar decompression: multi-institutional analysis of 7016 patients. J Neurosurg Spine 20:606-616, 2014

16. Leaper DJ, Tanner J, Kiernan M, Assadian O, Edmiston CE Jr: Surgical site infection: poor compliance with guidelines and care bundles. Int Wound J 12:357-362, 2015

17. McCormack RA, Hunter T, Ramos N, Michels R, Hutzler L, Bosco JA: An analysis of causes of readmission after spine surgery. Spine (Phila Pa 1976) 37:1260-1266, 2012

18. McCormack R, Michels R, Ramos N, Hutzler L, Slover JD, Bosco JA: Thirty-day readmission rates as a measure of quality: causes of readmission after orthopedic surgeries and accuracy of administrative data. J Healthc Manag 58:64-77, 2013

19. McCutcheon BA, Ciacci JD, Marcus LP, Noorbakhsh A, Gonda DD, McCafferty R, et al: Thirty-day perioperative outcomes in spinal fusion by specialty within the NSQIP database. Spine (Phila Pa 1976) 40:1122-1131, 2014

20. Medicare Payment Advisory Commission: Report to the Congress, June 2008: Reforming the Delivery System. Washington, DC: Medicare Payment Advisory Commission, 2008

21. Pugely AJ, Martin CT, Gao Y, Ilgenfritz R, Weinstein SL: The incidence and risk factors for short-term morbidity and mortality in pediatric deformity spinal surgery: an analysis of the NSQIP pediatric database. Spine (Phila Pa 1976) 39:1225-1234, 2014

22. Pugely AJ, Martin CT, Gao Y, Mendoza-Lattes S: Causes and risk factors for 30-day unplanned readmissions after lumbar spine surgery. Spine (Phila Pa 1976) 39:761-768, 2014

23. Richmond JC: CORR Insights: Impact of preoperative 
MRSA screening and decolonization on hospital-acquired MRSA burden. Clin Orthop Relat Res 471:2372-2373, 2013

24. Sacks GD, Dawes AJ, Russell MM, Lin AY, Maggard-Gibbons M, Winograd D, et al: Evaluation of hospital readmissions in surgical patients: do administrative data tell the real story? JAMA Surg 149:759-764, 2014

25. Schairer WW, Carrer A, Deviren V, Hu SS, Takemoto S, Mummaneni $\mathrm{P}$, et al: Hospital readmission after spine fusion for adult spinal deformity. Spine (Phila Pa 1976) 38:16811689,2013

26. Schairer WW, Carrer A, Sing DC, Chou D, Mummaneni PV, $\mathrm{Hu}$ SS, et al: Hospital readmission rates after surgical treatment of primary and metastatic tumors of the spine. Spine (Phila Pa 1976) 39:1801-1808, 2014

27. Seicean A, Alan N, Seicean S, Neuhauser D, Benzel EC, Weil RJ: Surgeon specialty and outcomes after elective spine surgery. Spine (Phila Pa 1976) 39:1605-1613, 2014

28. Sethi RK, Pong RP, Leveque JC, Dean TC, Olivar SJ, Rupp SM: The Seattle Spine Team approach to adult deformity surgery: a systems-based approach to perioperative care and subsequent reduction in perioperative complication rates. Spine Deform 2:95-103, 2014

29. Spagnolo AM, Ottria G, Amicizia D, Perdelli F, Cristina ML Operating theatre quality and prevention of surgical site infections. J Prev Med Hyg 54:131-137, 2013

30. Toy JO, Basques BA, Grauer JN: Morbidity, mortality, and readmission after vertebral augmentation: analysis of 850 patients from the American College of Surgeons National Surgical Quality Improvement Program database. Spine (Phila Pa 1976) 39:1943-1949, 2014

31. Vaziri S, Cox JB, Friedman WA: Readmissions in neurosurgery: a qualitative inquiry. World Neurosurg 82:376-379, 2014

32. Voskuijl T, Hageman M, Ring D: Higher Charlson Comorbidity Index Scores are associated with readmission after orthopaedic surgery. Clin Orthop Relat Res 472:1638-1644, 2014

33. Wang MC, Shivakoti M, Sparapani RA, Guo C, Laud PW, Nattinger AB: Thirty-day readmissions after elective spine surgery for degenerative conditions among US Medicare beneficiaries. Spine J 12:902-911, 2012

34. Yoshihara H, Yoneoka D: Incidental dural tear in spine surgery: analysis of a nationwide database. Eur Spine J 23:389-394, 2014

\section{Disclosure}

James Bernatz has no disclosures. Dr. Paul Anderson has the following declarations: Aesculap (data safety board), Stryker (royalties and consultation), Expanding Orthopedics (stock options), Titan Spine (stock options), Pioneer Surgical (stock options, royalties, and consultation), Spartec (stock options), and SI Bone (stock). This does not alter our adherence to the Journal of Neurosurgery's policies on sharing data and materials.

\section{Author Contributions}

Conception and design: both authors. Acquisition of data: Bernatz. Analysis and interpretation of data: both authors. Drafting the article: Bernatz. Critically revising the article: both authors. Reviewed submitted version of manuscript: Bernatz. Approved the final version of the manuscript on behalf of both authors: Bernatz. Statistical analysis: Anderson. Administrative/ technical/material support: Anderson. Study supervision:

Anderson.

\section{Correspondence}

James Bernatz, UW Medical Foundation Centennial Building, 1685 Highland Ave., 6th Fl., Madison, WI 53705-2281. email: jbernatz@wisc.edu. 